\title{
Analysis on Harm of Device Violation
}

\author{
Zhao Xinhua, Zhu Bo, Wang Chuang, Huang Yanhai, Ge Changxin, Hao Guanqiao, Wang \\ Xue, Zhang Wei, Xie Xinnan, Hao Wenfeng
}

Fushun Power Supply Company, Liaoning Electric Power Company Limited, State Grid, China

\begin{abstract}
Keywords: Device violation, Safety train, No violation, Habitual violation
\end{abstract}
\begin{abstract}
Device violation refers to tools and safety protection for production equipment, facilities, environment and operations, but it doesn't meet the requirements of regulation, stipulation, standard and anti-accident measure, which can't guarantee unsafe factor of reliably person, power grid and device safety. There are 19 cases of installation violations. and it states the hazard of device violation. The anti-device violation work should be around the five links of "prevention, inspection, correction, punishment and training", through continuous improvement of rules and regulations, and strengthening education training, the company organizes "no violation of enterprises", "no violation of regulations" and "no violation of employees" activities. Through analyzing the case, the importance of anti-devices violation is illustrated.
\end{abstract}

\section{Introduction}

Device violation is tools and safety protection for production equipment, facilities, environment and operations, but it doesn't meet the requirements of regulation, stipulation, standard and anti-accident measure, and can't guarantee unsafe factor of reliably person, power grid and device safety. The reasons for device violation are analyzed, violation expression is discussed, relevant control measures are formulated, all kinds of violations are eliminated fully in the power grid production, accident is reduced, then it is important and realistic meaning for healthy, sustained and stable development of power grid enterprise. ${ }^{[2]}$

\section{Device Violation Performance}

(1) There isn't enough safe distance from the high or low voltage line to the ground and construction.

(2) The energized part of high voltage distribution installation can't meet the relevant rules for the ground distance and take action.

(3) Metal enclosed switchgear doesn't design and manufacture pressure release channel according to national and industry standard.

(4) Standby interval isn't included in the dispatching jurisdiction.

(5) The energized part is still left untreated after the power equipment is dismantled.

(6) There are not safety precautions in the substation.

(7) There are not enough fireproofing facilities in the inflammable and explosive area, important fire zone, or it doesn't fit the rules.

(8) Primary connection and technical protocol are not in accordance with the design drawing.

(9) There is not safety warning sign in the power equipment or fixed cover (enclosure) is set in accordance without the relevant procedures.

(10) There is no double name for switchgear.

(11) There are not line name and bar number for line tower, or the name and the bar number are not unique, not correct and clear.

(12) The ground resistance is not qualified or overhead ground wire doesn't lead to the ground.

(13) There is no color code for the parallel or quadruple-circuits on the single tower line.

(14) Electric ground ring is set without the relevant regulations on the insulated distribution line.

(15) There are not enough anti-misoperation locking devices or the "five defense" function. 
(16) There is no shield on the rotating part of mechanical equipment.

(17) Electrical equipment housing isn't earthed.

(18) There is no leakage protector for temporary source.

(19) Hoisting machinery, such as: winching, truck crane, winch, a back stop device or brake rigging is unstuck, insensitive.

\section{The Hazard of Device Violation}

Device violation is a bad behavior, so it is essentially a blind behavior and it violates the objective laws of safety production. It isn't realized, and does whatever who wants. This behavior is a potential hazard, it is easy to occur to an accident in the ripe case, causing loss of life and property. In order to understand the hazard of device violation, we enumerate the following case for analysis.

\section{Case of Device Violation}

On March 11th, when watchman Wang, Huang looked over Zhenjiang 220kV substation, they found 10kV1 capacitor 961 switch spring energy wasn't full, abnormal flaws of control loop, they reported to the station master and the maintenance personnel of the company immediately. At 9:53 on March 12th, Meishan regional scheduling Zhang commanded "turn the 10kV1 capacitor 961 circuit breaker from hot standby to cold standby” by phone. At 10:03, Zhenjiang 220kV substation watchman Yuan, guardian Yao, leader Wang operated 09016 operation order(operation tasks: 10kV capacitor 961 circuit breaker from hot standby to cold standby). When they operated the fifth steps “open 1 capacitor 9611 isolating switch”, they checked that isolating switch handle and instructions were brake location, but didn't check isolating switch contact seriously. After the operation, they gave a report to regional scheduling Zhang. At 10:06, Zhang commanded by phone that safety measures for $10 \mathrm{kV}$ capacitor 961 circuit breaker were added based on the first kind of work ticket jianJ03-12. At 10:22, Zhenjiang 220kV substation watchman Yuan, guardian Yao, leader Wang operated 09017 operation order, when they closed the 96110 grounding switch of 1 capacitor, they found that there was an astringent phenomenon and gave a report to leader Wang, he didn't check actual location of the 9611 isolation switch carefully at the scene, and agreed to continue operation, then caused three-phase grounding short circuit. The cupboard door of 10kV1 capacitor 961switch was bounced off and $10 \mathrm{kV}$ phase bus bridge was touched, its differential protection acted, 202 circuit breaker, 102 circuit breaker, 902 circuit breaker tripped, then $110 \mathrm{kV}$ II bus and $10 \mathrm{kV}$ II bus pressured loss, automatic switch of Zhenjiang $110 \mathrm{kV}$ substation acted correctly, and it did not cause load loss.

The accident caused 961circuit breaker, 9611isolation switch and the rear cabinet door were damaged, insulation of current transformer was damaged, 961 control cables were damaged, and the remaining adjacent devices were not abnormal.

\section{Cause of the Accident}

(1) Transmission shaft of $10 \mathrm{kV}$ capacitor 9611 isolation switch was bending deformation, opening brake of 9611 isolation switch wasn't in place, operation interlocking mechanism couldn't close grounding switch normally, happening to close grounding switch with the electricity, so it is the direct reason of the accident.

(2) The duty operator violated the rules of switching operation, didn't check 9611 isolation switch operated actual location carefully, the location of the isolation switch is judged by open-close indicator, so it is the main reason of the accident.

(3) Since 2007, 961 switch (Kexing electric appliance co. LTD Chengdu, model YB-10) existed in safety hazard of device violation, and the charging display device is not reasonable, so it is the minor reason of the accident. 


\section{Work Requirements for Anti-Device Violation}

\subsection{Setting up Anti-Violation Work Mechanism}

Anti-violation work should be around the five links of "prevention, inspection, correction, punishment and training", through continuous improvement of rules and regulations, education training are strengthened, supervision and inspection are enhanced, penalties are increased, and a normal anti-violation working mechanism is established. According to the power grid enterprise security work deployment, the work experience of anti-violation activities are summarized, special activities for safe production is carried out, and "no violation of enterprises", "no violation of regulations" and "no violation of employees" activities are organized. The model of compliance is publicized vigorously and work experience is exchanged widely in anti-violation. These activities will form a party political and industrial group to share the atmosphere. ${ }^{[1]}$

\subsection{Consummating Security Administration Rules and Regulations}

The rules and regulations on production safety are revised and supplemented in time based on national laws and regulations and safety production requirements at all levels, advances in technology, change of management mode, countermeasure and so on. Violations are prevented from organizational management, technical measures and system construction.

\subsection{Improving the Safety Training Mechanism}

Safety rules and regulations, safety technical skills, safety management and supervision are carried out at the hierarchical level, profession, type of work. From the safety quality and skills training, these methods can improve the personnel ability of identification, preventing violation and correcting violation at all levels.

\subsection{Carrying out Safety Production Guarantee System}

The system of leading cadres and managers will be implemented strictly in place, safety production guarantee system frequency and requirements of all levels responsible person, manager and safety inspectors are cleared, and supervision and inspection of production safety are carried out.

\subsection{Carrying out Violation Self-Correction}

The shift system of the team safety supervisor and personal safety points system are implemented actively, the enthusiasm and initiative of basic team and employees are mobilized fully, production practice is combined closely, employees are encouraged to find the violation independently, the violation is corrected consciously, the violation is supervised and rectified each other.

\subsection{Performing Violation Articulate System}

For every violation, the reasons are analyzed clearly, responsibility is carried out to person, corrective action is in place. For the repeat same kind of property violation and the violation of unsafe events, the responsibility unit shall go to the superior unit to "make it clear". ${ }^{[3]}$

\subsection{Establishing Violation Exposure System}

Anti-violation work columns will be opened up on the website, in the press and briefing, accident monitoring, the security checking, special supervision and violation of picket violation phenomena exposure, anti-violation public opinion supervision atmosphere is formed.

\subsection{Implementing Violation Points Assessment}

According to the type of violation and violation nature, the classification is made to reduce the score and anti-violation bonus rules, violation scores are put into individual and unit safety assessment as a basis for the advanced selection. 


\subsection{Carrying out the Violation Personnel Education Training}

For the serious offenders, education training should be focused on, the causing accidents persons should be trained for education by serious violation or violation regulations, jobs are being repossessed after passing the examination.

\subsection{Conducting Statistical Analysis of Violations}

Security departments take month, season, year as the cycle, violations phenomenon is counted, the reasons are analyzed for the violation, preventive measures are researched and developed, relevant circumstances are briefed at the safety supervision regular meeting, safety monthly meeting, security council meeting, the relevant information is reported to the supervisor.

\subsection{Implementing the Anti-Violation Reporting System}

Security inspectors fill in the safety audit report in time, and report the work report and all kinds of notifications to the security department of the unit.

\section{Conclusions}

(1) Supervision and inspection of anti-violation work will be strengthened, superior inspection on subordinates are performed, the security production supervision system at the same level shall supervise the guarantee system.

(2) Anti-violation supervision and inspection actively carry out centralized audit and cross-check through accident monitoring,

(3) The units shall be equipped with the necessary equipment to supervise and inspect the professional security audit institutions (such as photograph, photographic equipment, telescope), the using of vehicles is ensured, supervision and inspection efficiency and quality is improved.

(4) Anti-violation supervision and inspection follow the steps of "inspection, notification, punishment and rectification". Once inspectors at all levels find the violation, should stop, correct, explain the basis of the violation instantly, the violation record is made, a notice of punishment or rectification notice to the relevant unit or team is issued, corrective actions are supervised and implemented.

(5) During the inspection process, personnel at all levels find the violation and don't stop it, these behaviors are regarded as violation of regulations.

(6) An online publishing system should be established for job information, it is published in advance (operation schedule), assignment, time, people, place are cleared, supervision and inspection are accepted actively. According to the nature of site work, working face and risk, full-time security inspection teams determine the audit object.

\section{References}

[1] Yi Hu, State grid corporation Wuhan high pressure institute, Electrification of distribution lines. Beijing: China electric power press, 2002.

[2] Hongyun Yu, Li Rui. Anti-falling technology for high power operation. Beijing: China electric power press, 2008.

[3] Xuenong Huang, Training materials for safety management personnel of power grid enterprises. Beijing: Electronic industry press, 2014. 